\title{
In vitro Effects of Some Thai Anthelmintic Plants on Mortality and Change of Tegumental Surface of Stellantchasmus falcatus
}

\author{
Kittisak Buddhachat, Kittichai Chantima, Siriwadee Chomdej and Chalobol Wongsawad*
}

Department of Biology, Faculty of Science, Chiang Mai University, Chiang Mai, Thailand

\begin{abstract}
Several Thai herbs have been used to treatment of parasite infection according to the Thai Pharmacopoeia. To verify their anthelmintic activity scientifically, Stellantchasmus falcatus was used as model to test their activity. The activity of aqueous extracts of papaya (Carica papaya Linn.) seeds and bitter cucumber (Mormordica charantia Linn.) fruits were studied by using mortality and tegumental surface change on $\mathrm{S}$. falcatus. The worms were incubated in $12.5 \%, 50 \%$ and $100 \%(0.47,1.88$ and $3.15 \mathrm{mg} / \mathrm{ml}$ for papaya seed extract respectively, $7.5,30$ and $60 \mathrm{mg} / \mathrm{ml}$ for bitter cucumber extract, respectively) aqueous herbal extracts and in Tyrode's solution as control. As a result, the aqueous extract of papaya seeds tended to have more anthelmintic activity than that of bitter cucumber fruits due to much less concentration of papaya seed extract was required to kill the total worms than the bitter cucumber fruit extract. Besides, scanning electron microscopic was performed to observe change of tegumental surface of dead worm treated by those extracts. Consequently, those worms treated with aqueous extract of papaya seeds showed loss of spine, especially around the oral sucker and posterior region; whereas curving at the edge of the spines, blebbing and rupturing at the body surface were observed in the worms exposed to both papaya seed and bitter cucumber fruit extracts. The aqueous extracts of papaya seeds and bitter cucumber fruits have anthelmintic activity which can be used in treatment of parasite infection.
\end{abstract}

Keywords: Anthelmintic; Bitter cucumber; Papaya; Scanning electron microscope; Stellantchasmus falcatus; Tegumental surface

\section{Introduction}

Stellantchasmus falcatus, a species of fluke in the Family Heterophyidae, is a minute intestinal trematode of fish-eating birds and mammals. Human infections with this fluke have been reported in Hawaii [1], Philippines [2], Japan [3], Thailand [4] and Korea [5]. The S. falcatus metacercariae or infective stage is commonly found in freshwater fish such as Mugil sp. [5], Xenetodon cancila [6] and Dermogenus pusillus [7]. In Thailand, five species of flukes i.e. Haplorchis pummilio, H. taichui, H. yokogawai, S. falcatus and Centrocestus caninus were found responsible for human infections $[8,9]$ due to the consumption of raw or undercook fish.

Some medical properties of bitter cucumber (Mormordica charantia Linn.) include antiviral, antibacterial, anti-inflammatory, immunestimulant, insecticidal and anthelmintic properties. A bitter cucumber has been used to study about the anthelmintic activity on Ascaridia galli and Plasmodium berghei as antimalarial agent. A bitter cucumber ( $M$. charantia Linn.) was shown that it was safe in experimental animals when ingested at low doses up to 2 months [10]. Previous study has confirmed that various preparations of papaya (Carica papaya Linn.) seeds can against helminthes effectively in vitro and in infected animals. Bioactive compounds responsible for the anthelmintic properties were ascribed to carpaine, carpasemine and benzyl isothiocyanate [11]. Most importantly, both papaya seeds and bitter cucumber fruits are cheap and easily available in tropical countries. However, there is no report that study regarding the effect of both extract of papaya seeds and bitter cucumber fruits on tegumetal surface of helminthes. Thus, this study is the first paper that study anthelmintic activity of both papaya seeds and bitter cucumber fruits on $S$. falcatus by observation under a Scanning Electron Microscope (SEM).

\section{Materials and Methods}

Preparation of the aqueous extract of papaya seeds and bitter cucumber fruits

The aqueous extract of papaya seeds and bitter cucumber fruits were prepared according to the Thai Pharmacopoeia. Papaya seeds, 0.75 grams were dried and boiled in distilled water until the volume was $200 \mathrm{ml}(3.75 \mathrm{mg} / \mathrm{ml})$ then filtered through a sieved cloth to obtain a $100 \%$ stock solution. Twelve grams of bitter cucumber fruits was chopped and boiled in distilled water until the volume was $200 \mathrm{ml}(60$ $\mathrm{mg} / \mathrm{ml}$ ) and then filtered through a sieved cloth to get a $100 \%$ stock solution. The $100 \%$ stock solution was diluted in Tyrode's solution to give $12.5 \%$ and $50 \%$ concentration.

\section{Adult Stellantchasmus falcatus preparation}

The chicks (Gallus gallus domesticus) were orally force fed with half-beaked fish (Dermogenus pusillus) infected with metacercariae of $S$. falcatus. Three days later, adult worms were collected from the small intestine of the chicks with Baremann's apparatus and washed with $0.85 \% \mathrm{NaCl}$ solution. The worms obtained were stored in Tyrode's solution.

\section{Experimental design}

Thirty adult worms were individually incubated in Petri-dish containing $5 \mathrm{ml}$ of Tyrode's solution, $12.5 \%, 50 \%$ and $100 \%$ aqueous extract from papaya seeds and bitter cucumber fruits. All the plates were incubated at room temperature until all of the worms were killed. The death and movement of the worms were examined under light

*Corresponding author: Chalobol Wongsawad, Department of Biology, Faculty of Science, Chiang Mai University, Chiang Mai, Thailand, Tel: +66 5394 1951; Fax +66 5389 2259; E-mail: cwongsawd@yahoo.com

Received March 27, 2012; Accepted August 27, 2012; Published August 30, 2012

Citation: Buddhachat K, Chantima K, Chomdej S, Wongsawad C (2012) In vitro Effects of Some Thai Anthelmintic Plants on Mortality and Change of Tegumental Surface of Stellantchasmus falcatus. J Bacteriol Parasitol 3:146. doi:10.4172/2155 9597.1000146

Copyright: (c) 2012 Buddhachat K, et al. This is an open-access article distributed under the terms of the Creative Commons Attribution License, which permits unrestricted use, distribution, and reproduction in any medium, provided the original author and source are credited. 
microscope. The worms were described as dead when no movement was observed within 10 seconds.

\section{Scanning electron microscopy}

The dead worms were processed for SEM, fixed in $2.5 \%$ glutaraldehyde at $4^{\circ} \mathrm{C}$ for 24 hours and then fixed with $1 \%$ osmium tetroxide, followed by conventional methods and observed with SEM (JEOL JSM-5400LV at $10 \mathrm{KV}$ ).

\section{Results}

Aqueous extract of papaya seeds at the different concentrations of $12.5 \%, 50 \%$ and $100 \%$ were able to kill all the worms at 300,275 , and 55 minutes respectively, and the aqueous extract of bitter cucumber fruits at the concentration of $12.5 \%, 50 \%$ and $100 \%$ were able to kill all of the worms at 280, 270 and 80 minutes respectively, whereas the worms in Tyrode's solution as control were all killed at 650 minutes (Figure 1). Therefore, the aqueous extracts of both papaya seeds and bitter cucumber fruits were able to kill worms more rapidly than that of the control group. When compared the individual concentrations, there was no significant difference in the activities of both papaya seed and bitter cucumber fruit extracts $(\mathrm{P}<0.05)$. The extracts at $100 \%$ concentration required less time to kill all the worms than those at $50 \%$ and $12.5 \%$ concentration. Interestingly, $100 \%$ concentration of papaya seed extract preparation used less raw material than bitter cucumber fruit extract. It might be possible that the aqueous extract of papaya seed has more anthelmintic substance than that of bitter cucumber fruit.

SEM observation of the tegumental surface of the control group indicated that it was covered with scale-like spines except around the excretory pore. Moreover, the sensory organs were crowded at the oral sucker (Figure 2A-2C). Dead worms in both aqueous extracts at $100 \%$ concentration were examined. Those tegumetal surface showed blebbing, curving at the edge of the spines (Figure 2D-2I). Although the pattern of the tegumental damage was similar to both extracts but the part of the worms that destroyed by both extracts were different. The aqueous extract of papaya seeds was noted for destruction of spines, especially around the oral sucker (Figure 2E).

\section{Discussion}

Wongsawad et al. [11] reported that Haplorchis taichui affected

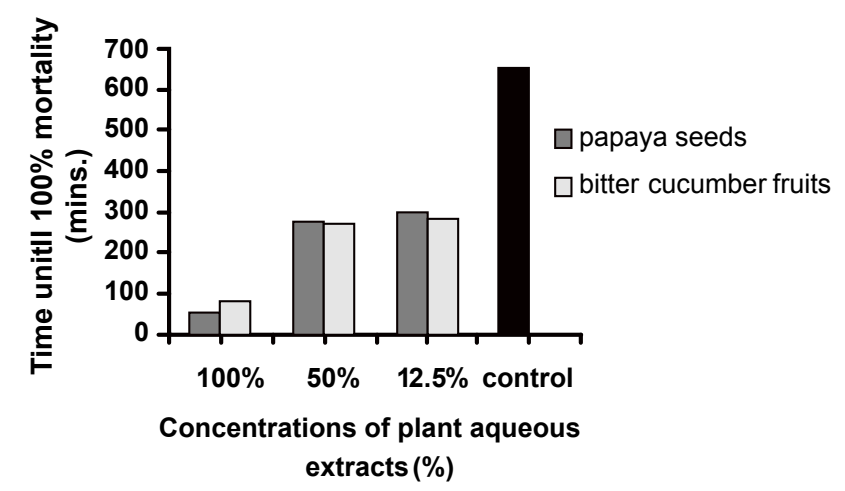

Figure 1: The effects of aqueous extract of papaya seeds and bitter cucumber fruits on the mortality of $S$. falcatus adults. $S$. falcatus adults were examined with only Tyrod's solution as control.
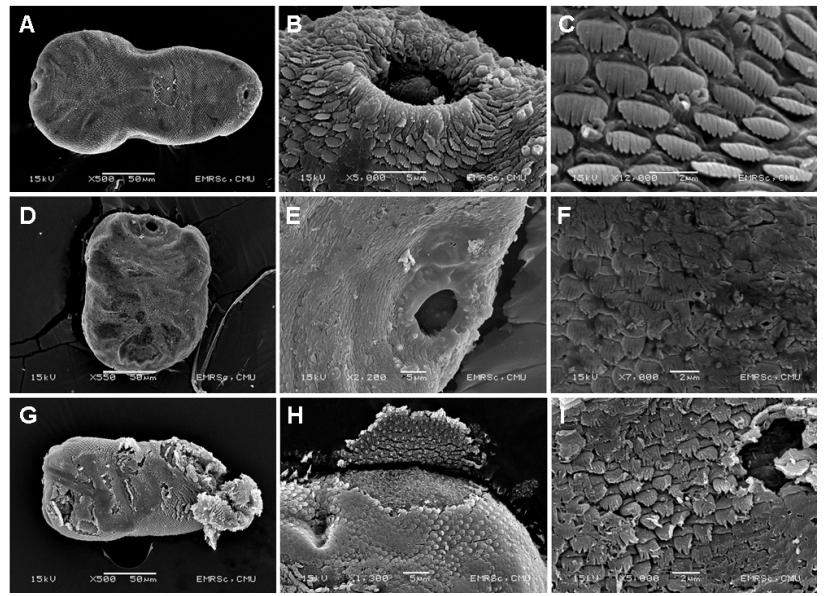

Figure 2: SEM micrograph of tegumental surface of adult Stellantchasmus falcatus (A-C) exposed in Tyrode's solution as control group; (A) Ventral surface, scale bar $(\mathrm{sb})=.50 \mu$. (B) Oral sucker, sb. $=5 \mu$. (C) Spine and sensory organ on anterior part of dorsal surface, sb. $=2 \mu$. (D-F) exposed in $100 \%$ aqueous extract of papaya seeds; (D) Ventral surface, sb. $=50 \mu$. (E) Loss of spines around the oral sucker, sb. $=5 \mu$. $(F)$ Blebbing, rupturing of the body surface and curving at the edge of the spines, sb. $=2 \mu$. (G-I) exposed in $100 \%$ aqueous extract of bitter cucumber fruits; $(G)$ Dorsal surface, sb. $=50 \mu$. $(\mathrm{H})$ Flanking of tegumental surface, sb. $=5 \mu$. (I) Blebbing, rupturing of the body surface and curving at the edge of the spines, sb. $=2 \mu$.

by Artocarpus lakoocha Roxb. developed rupturing and loss of spines similar to this study. The activity of both papaya seed and bitter cucumber fruit extracts did not cause swelling of $S$. falcatus. The blebbing of the worms when treated with bitter cucumber extracts (Figure 2I) was the same as that of Haplorchis taichui treated with A. lakoocha Roxb. [12] and the effect of praziquantel on Fibricola seoulensis [13]. The functional roles of the tegumental surface are for attachment and nutrient uptake from the host [14]. It is possible that the worms were released from epithelial tissue of host small intestine when their tegument was damaged by anthelmintic medication. Also, the damage of the tegument along the worm body could impair and destroy the worm defense system, making it susceptible to the host immune system as one function of the tegumental is against immune invasion $[14,15]$. Subsequently, their tegument is an important target for anthelmintic drugs. Additional in vivo experiment is necessary to confirm its anthelmintic activity.

The chemicals in the aqueous extracts of both papaya seeds and bitter cucumber fruits might be associated with various physiological properties of the tegument of S. falcatus. In papaya seeds, bioactive compound such as benzyl isothiocyanate may be considered responsible for killing Caenorhabditis elegans [11]. Lal et al. [15] found that bitter cucumber exhibited in vitro anthelmintic activity against $A$. galli worms and more effective than piperazine hezahydrate. Further study on the active compounds in the papaya seeds and bitter cucumber fruits are suggested due to their potential use as an alternative anthelmintic medication for human infection and this information is particularly important for health care.

\section{Acknowledgement}

The authors would like to thank Thailand Science Scholarship Program for financial support, the Parasitology Research Laboratory, Department of Biology, the Electron Microscope Research and Service Center, Faculty of Science, the Applied Technology for Biodiversity Research Unit, the Institute for Science and Technology Research, Chiang Mai University for access to instruments and facilities. Special thank go to Thanapol Yooyen for valuable help. 
Citation: Buddhachat K, Chantima K, Chomdej S, Wongsawad C (2012) In vitro Effects of Some Thai Anthelmintic Plants on Mortality and Change of Tegumental Surface of Stellantchasmus falcatus. J Bacteriol Parasitol 3:146. doi:10.4172/2155-9597.1000146

Page 3 of 3

\section{References}

1. Alicata JE, Schattenburg OL, Honolulu TH (1938) A case of intestinal heterophyidiasis of man in Hawaii. JAMA 110: 1100-1101.

2. Africa CM, de Leon W, Garcia EY (1940) Visceral complications in intestinal heterophyidiasis of man. International Congress $\left(3^{\text {rd }}\right)$ for Microbiology, New York. 1: $447-449$

3. Kagei N, Oshima T, Ishikawa K, Kihata M (1964) Two cases of human infection with Stellantchasmus falcatus Onji et Nishio, 1915 (Heterophyidae) in Kochi prefecture. Jpn J Parasitol 13: 472-478.

4. Tantachamrun T, Kliks M (1978) Heterophyid infection in human ileum: report of three cases. Southeast Asian J Trop Med Public Health 9: 228-231.

5. Giboda M, Ditrich O, Scholz T, Viengsay T, Bouaphanh S (1991) Current status of food-borne parasitic zoonoses in Laos. Southeast Asian J Trop Med Public health 22: 56-61.

6. Wongsawad C, Chariyahpongpun P, Namue C (1998) Experimental host of Stellantchasmus falcatus. Southeast Asian J Trop Med Public health 29: 406-409.

7. Waikagul J (1991) Intestinal fluke infections in Southeast Asia. Southeast Asian J Trop Med Public Health 22: 158-162.

8. Waikagul J, Wongsaroj T, Radomyos P, Meesomboon V, Praewanich R, et al.
(1997) Human infection of Centrocestus caninus in Thailand. Southeast Asian J Trop Med Public Health 28: 831-835.

9. Grover JK, Yadav SP (2004) Pharmacological actions and potential uses of Momordica charantia: a review. J Ethnopharmacol 93: 123-132.

10. Kermanshai R, McCarry BE, Rosenfeld J, Summers PS, Weretilnyk EA, et al. (2001) Benzyl isothiocyanate is the chief or sole anthelmintic in papaya seed extracts. Phytochemistry 57: 427-435.

11. Wongsawad C, Wongsawad P, Luangphai $P$, Kumchoo K (2005) In vitro effects of aqueous extract from Artocarpus takoocha Roxb on tegumental surface of Haplorchis taichui. Southeast Asian J Trop Med Public Health 4: 112-116.

12. Lee SH (1985) In vitro effects of praziquantel on Fiblicola seoulensis. Korean J Parasitol 26: 41-51.

13. Van Hellemond JJ, Retra K, Brouwers JF, van Balkom BW, Yazdanbakhsh M, et al. (2006) Functions of the tegument of schistosomes: clues from the proteome and lipidome. Int J Parasitol 36: 691-699.

14. Jiraungkoorskul W, Sahaphong S, Sobhon P, Riengrojpitak S, Kangwanrangsan N (2005) Effects of praziquantel and artesunate on the tegument of adult Schistosoma mekongi harboured in mice. Parasitol Int 54: 177-183.

15. Lal J, Chandra S, Raviprakash V, Sabir M (1976) In vitro anthelmintic action of some indigenous medicinal plants on Ascardia galli worms. Indian J Physiol Pharmacol 20: 64-68. 